\title{
Need for closure of secundum atrial septal defect in infancy
}

\author{
Astrid Lammers, ${ }^{a}$ Alfred Hager, MD, ${ }^{a}$ Andreas Eicken, MD, ${ }^{a}$ Rüdiger Lange, MD, ${ }^{\mathrm{b}}$ Michael Hauser, $\mathrm{MD},{ }^{\mathrm{a}}$ and \\ John Hess, MD, FESC
}

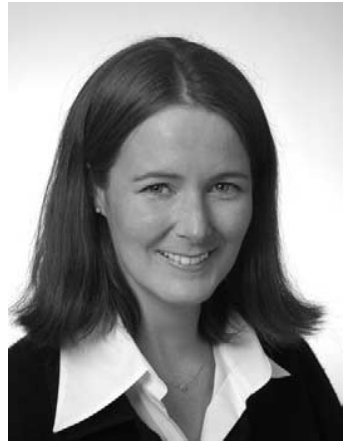

Astrid Lammers
Objectives: Closure of isolated secundum atrial septal defect is generally recommended at the age of 4 to 5 years. However, there are children with isolated secundum atrial septal defect in whom early closure should be performed. We aimed to assess the underlying conditions that led to earlier closure in this special patient group and to analyze the outcome.

Methods and Results: From January 1990 through August 2002, 24 infants with isolated secundum atrial septal defect underwent surgical closure within the first year of life. All children were symptomatic. Signs of pulmonary hyperperfusion, such as tachydyspnea, failure to thrive, recurrent respiratory infections, or heart failure, were present. Four infants required artificial ventilation. Ten patients had additional problems, such as prematurity with chronic lung disease, hepatoomphalocele and congenital diaphragmatic hernia, which were present in 1 patient each. Eleven patients had defined dysmorphic syndromes. All but 1 infant underwent preoperative invasive hemodynamic evaluation. Thirteen patients had pulmonary hypertension preoperatively. The follow-up time was $46 \pm 33$ months (range, 4-125 months). At follow-up, pulmonary artery pressure proved to be normal in 11 of the 13 children who had pulmonary hypertension previously. One patient died of persistent pulmonary hypertension. Clinical performance, growth, and development improved in nearly all patients. All ventilator-dependent children could be weaned shortly after atrial septal defect closure.

Conclusions: If lungs are compromised, even a minor left-to-right shunt might be poorly tolerated in infancy. In these children early surgical closure of an isolated secundum atrial septal defect should be performed to support thrive and growth and to prevent the onset of irreversible changes of the pulmonary vasculature.

A trial septal defect (ASD) is a common congenital heart defect with an incidence of $7 \%{ }^{1}$ Atrial left-to-right shunting is well tolerated in otherwise healthy children, and the majority of patients with isolated secundum atrial septal defect (ASD II) remain asymptomatic in infancy and childhood. Usually there is neither pulmonary hypertension nor an increase of pulmonary vascular resistance (PVR) at that age. Typically, closure of isolated ASD II is undertaken in the fourth or fifth year of life, preferably through interventional device closure. ${ }^{2}$ However, there is a group of patients who undergo ASD closure much earlier in life. These patients present with severe problems during infancy, such as recurrent respiratory infections, failure to thrive, heart failure, and respiratory insufficiency necessitating artificial ventilation. This study was initiated to describe the conditions that led to the decision of early closure and to determine whether these conditions were resolved by means of closure of the defect. Because device closure in the first year of life is not feasible, early closure refers to surgical intervention. 
TABLE 1. Patients' characteristics at the time of surgical intervention

\begin{tabular}{|c|c|c|c|c|c|c|c|}
\hline No. & Extracardiac diagnosis-problems & Age (mo) & $\begin{array}{l}\text { Weight } \\
\text { (kg) }\end{array}$ & $\begin{array}{c}\text { Mean PAP } \\
\text { (mm Hg) }\end{array}$ & PAP/AoP & $\begin{array}{c}\mathbf{Q p} / \mathbf{Q} \mathbf{s} \\
\left(\mathrm{L} \cdot \mathrm{min}^{-1} \cdot \mathrm{m}^{-2}\right)\end{array}$ & $\begin{array}{c}\mathrm{Rp} \\
\left(\mathrm{E} \cdot \mathrm{m}^{2}\right)\end{array}$ \\
\hline 1 & - & 3.8 & 4.8 & 16 & 0.33 & 3.00 & 1.5 \\
\hline 2 & $\begin{array}{l}26 \text { WGA, hydrocephalus, psychomotor } \\
\text { retardation }\end{array}$ & 7.3 & 4.1 & 24 & 0.46 & 1.38 & 3.6 \\
\hline 3 & Median cleft syndrome & 8.9 & 6.8 & 27 & 0.45 & 1.70 & 3.4 \\
\hline 4 & Trisomy 21, immunodeficiency syndrome & 6.3 & 4.8 & 64 & 0.88 & 1.17 & 11.6 \\
\hline 5 & $\begin{array}{l}\text { Noonan syndrome, congenital } \\
\text { diaphragmatic hernia }\end{array}$ & 6.9 & 4.7 & 40 & 0.67 & 1.91 & 4.5 \\
\hline 6 & 32 WGA, CHARGE syndrome & 11.6 & 6.2 & 26 & 0.54 & 2.50 & 1.9 \\
\hline 7 & Trisomy 21 , lung sequester & 9.7 & 5.4 & 43 & 0.67 & 3.95 & 1.2 \\
\hline 8 & $\begin{array}{l}\text { Laryngomalacia, stenosis of left main } \\
\text { bronchus }(70 \%)\end{array}$ & 8.4 & 8.9 & 17 & 0.33 & 2.60 & 1.4 \\
\hline 9 & $\begin{array}{l}\text { Atrial tachycardia, microcephalus, } \\
\text { amaurosis }\end{array}$ & 10.6 & 6.0 & 48 & 0.57 & 2.10 & 1.4 \\
\hline 10 & - & 6.1 & 8.8 & 48 & 0.68 & 2.67 & 4.0 \\
\hline 11 & 25 WGA & 4.0 & 2.5 & - & - & - & - \\
\hline 12 & 36 WGA, arthrogryposis multiplex congenita & 4.9 & 5.3 & 18 & 0.38 & 2.00 & 2.0 \\
\hline 13 & Hallermann-Streiff syndrome & 8.2 & 4.9 & 33 & 0.67 & 1.64 & 4.2 \\
\hline 14 & Noonan syndrome, psychomotor retardation & 11.3 & 4.2 & 33 & 0.60 & 1.60 & 3.7 \\
\hline 15 & 36 WGA, hepato-omphalocele & 4.4 & 4.7 & 45 & 1.00 & 1.25 & 9.3 \\
\hline 16 & - & 2.5 & 4.7 & 48 & 0.86 & 1.75 & 8.7 \\
\hline 17 & 34 WGA, umbilical hernia & 6.7 & 4.7 & 26 & 0.40 & 1.60 & 1.8 \\
\hline 18 & $\begin{array}{l}32 \text { WGA, VACTERL association, } \\
\text { tracheomalacia }\end{array}$ & 4.4 & 3.2 & 19 & 0.48 & 3.33 & 0.8 \\
\hline 19 & SGA & 8.6 & 6.2 & 18 & 0.51 & 2.36 & 1.2 \\
\hline 20 & 33 WGA, asphyxia palladia & 9.2 & 7.1 & 12 & 0.22 & 1.07 & 1.6 \\
\hline 21 & Cleft palate, Pierre-Robin syndrome & 1.3 & 3.4 & 31 & 0.84 & 28.2 & 0.4 \\
\hline 22 & 35 WGA, trisomy 21 & 2.4 & 3.6 & 24 & 0.75 & 9.00 & 0.5 \\
\hline 23 & SGA & 4.6 & 4.5 & 15 & 0.46 & 4.00 & 0.9 \\
\hline \multirow[t]{3}{*}{24} & 31 WGA & 10.5 & 4.3 & 16 & 0.46 & 1.86 & 1.7 \\
\hline & Mean \pm SD & $6.4 \pm 3.3$ & $5.3 \pm 1.6$ & $30.0 \pm 13.6$ & $0.6 \pm 0.2$ & $3.7 \pm 5.6$ & $3.1 \pm 2.9$ \\
\hline & Range & 6.6 & 4.8 & 26 & 0.5 & 2 & 1.8 \\
\hline
\end{tabular}

$P A P$, Pulmonary artery pressure; $P A P / A o P$, systolic pulmonary pressure/systolic aortic pressure; $Q p$, pulmonary blood flow; $0 s$, systemic blood flow; $R p$, pulmonary resistance; WGA, weeks of gestational age; CHARGE, coloboma, heart disease, atresia choanae, retarded growth and retarded development and/or central nervous system anomalies, genital hypoplasia, and ear anomalies and/or deafness; VACTERL, vertebral abnormalities, anal atresia, cardiac abnormalities, tracheoesophageal fistula and/or esophageal atresia, renal agenesis and dysplasia, and limb defects; SGA, small for gestational age.

If ASD II remains untreated, pulmonary hypertension can be expected in one third of the patients in the third decade and in two thirds in the fourth decade of life. ${ }^{3-5}$ Other late problems of untreated ASD II are atrial dysrhythmia and heart failure. Overall, it is estimated that in the natural history of ASD, half of the patients who survived the first year of life will reach 37 years of age. ${ }^{5}$

\section{Patients and Methods \\ Patients}

We retrospectively reviewed the records of all 24 patients who underwent surgical closure of isolated ASD II within the first year of life from January 1990 through August 2002 in our hospital.

The mean age at closure was $6.7 \pm 2.9$ months (range, 1.3-11.6 months). There were 17 girls and 7 boys. The mean weight at the time of surgical intervention was $5.2 \pm 1.6 \mathrm{~kg}$ (range, $2.5-8.9 \mathrm{~kg}$ ). Before surgical intervention, all patients were symptomatic, show- ing signs of tachydyspnea and heart failure. Thirteen patients were long-standing hospital inpatients before they were scheduled for surgical ASD II closure. Four patients were dependent on artificial ventilation and could not be weaned preoperatively. Children who were admitted for surgical intervention had recurrent respiratory infections, which frequently led to intermittent hospitalization. Specific problems of the patients are outlined in Table 1.

Preoperatively, all but 1 infant underwent cardiac catheterization and angiography. The results showed that 13 patients had pulmonary hypertension, which was defined as a mean pulmonary artery pressure of greater than $25 \mathrm{~mm} \mathrm{Hg}$. Eight of these infants had an increased PVR calculated from the mean pressure gradient over the pulmonary vascular bed and pulmonary blood flow values obtained from oximetry by using the Fick principle. The PVR was moderately increased $\left(3-5\right.$ units $\left.\cdot \mathrm{m}^{2}\right)$ in 5 patients and severely increased $\left(>5\right.$ units $\left.\cdot \mathrm{m}^{2}\right)$ in 3 patients. In these 3 patients the PVR reactivity to oxygen was tested with a fraction of inspired oxygen 
of 1.0. In patient 4 , who died 6 months after surgical intervention, the PVR decreased from 11.6 to 3.8 units $\cdot \mathrm{m}^{2}$ with a fraction of inspired oxygen of 1.0. In patients 15 and 16 PVR decreased from 9.3 to 3.2 units $\cdot \mathrm{m}^{2}$ and from 8.7 to 3.2 units $\cdot \mathrm{m}^{2}$, respectively. The mean left-to-right shunt, also calculated on the basis of oximetry, was 52\%. A right-to-left shunt was found in 10 infants, and the mean right-to-left shunt was $3.9 \%$. In one of these patients a preoperative arterial oxygen saturation of $85 \%$ in room air was measured, but at cardiac catheterization, even this patient showed increased pulmonary blood flow. None of the other patients were cyanotic at rest.

\section{Follow-up Investigations}

All children participated in a follow-up investigation. All patient histories were taken with special emphasis on the children's ability to thrive and on general psychomotor development. They had complete physical examinations, electrocardiography, and chest radiography. Pulmonary artery pressure was evaluated noninvasively by means of echocardiography in all children. Because none of the patients had right ventricular outflow obstruction or pulmonary stenosis, the systolic pulmonary artery pressure was estimated from the peak flow velocity in the tricuspid regurgitation jet by using the modified Bernoulli equation. In patients without tricuspid regurgitation, the right ventricular pressure was assumed to be normal if the following echocardiographic criteria were present: no right ventricular hypertrophy or dilatation, no ventricular septal deviation, and normal pulmonary artery flow profile.

\section{Statistics}

All descriptive data are shown as means \pm SD (range). Weight and length were considered to be normally distributed. Z-scores of weight and length were calculated as follows: Z-score $=(\mathrm{Mea}$ sured value - Reference mean)/Reference $S D$.

Reference values were taken from Centers for Disease Control and Prevention growth charts. ${ }^{6}$ For the premature infants, age was corrected according to prematurity. We did not use any specific percentiles for infants with trisomy or for twins. A 2-tailed paired $t$ test was performed to compare data before surgical intervention with data from follow-up.

The clinical condition of the patients was defined as a treatment score as follows:

1. At home without anticongestive medication

2. At home with anticongestive medication

3. Hospitalized with medication and breathing spontaneously

4. Hospitalized with mechanical ventilation

5. Dead

A 2-tailed Wilcoxon test was performed to compare the treatment score before surgical intervention with the score at follow-up.

\section{Results}

\section{Surgical Strategy and Perioperative Mortality}

In 4 patients the ASD was closed with direct sutures, and in 20 patients a patch closure was performed. There was no perioperative mortality.

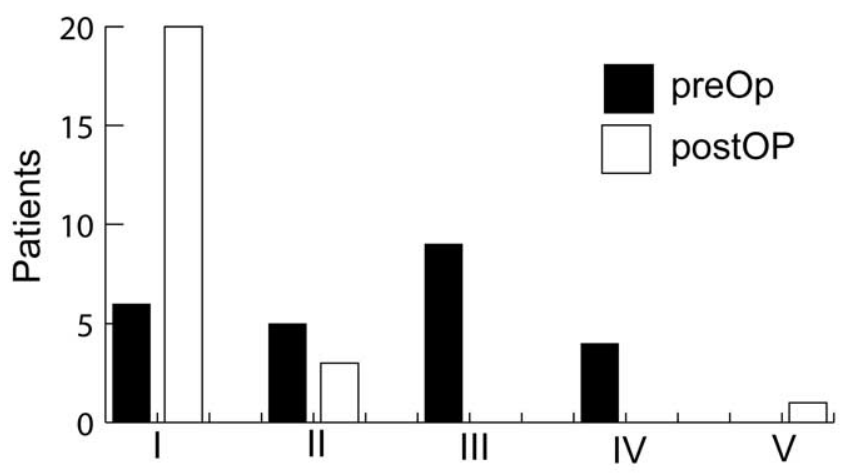

Figure 1. Self-defined treatment scores.

\section{Follow-up}

The mean follow-up period was $49 \pm 33$ months (range, 4-125 months). One patient died 6 months after surgical intervention. In this patient persistent pulmonary hypertension was diagnosed at follow-up 4 months after surgical intervention. Absolute weight $(5.2 \pm 1.7 \mathrm{~kg}$ before surgical intervention vs $16.2 \pm 9.1 \mathrm{~kg}$ after surgical intervention, $\mathrm{n}$ $=20, P<.0005)$ and length $(60.9 \pm 7.6 \mathrm{~cm}$ before surgical intervention vs $100.7 \pm 22.0 \mathrm{~cm}$ after surgical intervention, $\mathrm{n}=20, P<.0005)$ increased postoperatively. The increases in $z$ scores, representing the catch-up growth, were not significant (weight/z: $-2.6 \pm 2.2$ before vs $-2.0 \pm 2.6$ after, $\mathrm{n}=20, P=.30$; length $/ z:-1.8 \pm 1.8$ before vs -1.2 \pm 2.2 after, $\mathrm{n}=20, P=.27$ ). Nevertheless, in 14 patients a positive percentile change regarding weight and in 12 patients a positive percentile change regarding length was documented.

\section{Clinical Condition}

All children with feeding problems gained strength, started oral feeding (even those with feeding tubes), and thrived. All patients were weaned from the ventilator shortly after surgical intervention, even those patients who could not be weaned preoperatively (patients $2,6,11$, and 15). In particular, those children who were physically handicapped improved. In those children, indispensable physiotherapy, orthopedic treatment, or elective orthopedic surgery, which had previously been postponed because of a poor clinical situation, could be performed after ASD II closure.

Our self-defined treatment score also showed a significant improvement $(P<.005$, Figure 1). Nevertheless, there was one girl (patient 22) with trisomy 21 in whom persistent pulmonary hypertension was suspected on the basis of echocardiography 6 months after surgical intervention. She receives oxygen therapy at home and is scheduled for diagnostic cardiac catheterization. 


\section{Discussion}

This study shows that ASD closure can be performed safely without perioperative mortality in infants, even in the presence of severe comorbidity. Most patients showed a good functional outcome at follow-up. In general, ASD II with associated pulmonary hypertension and increased PVR is a rare finding in infancy and not solely a result of atrial left-to-right shunting. This suggests other substrates for the presence of pulmonary hypertension. In our study group, for example, diaphragmatic hernia with prenatal mechanical compression of the lungs led to pulmonary hypoplasia. In other infants chronic lung disease caused by prematurity was the reason for reduction of the total pulmonary vascular diameter. This condition might explain our hemodynamic findings of pulmonary hypertension. If other noncardiac malformations are present, it is impossible to determine the effect of left-to right shunting on growth and clinical symptoms. Increased pulmonary blood flow might further enhance the pulmonary vascular remodeling already induced by other factors and thus affect the clinical condition substantially.

Bull and colleagues ${ }^{7}$ suggested, in a similar patient group, that pulmonary vascular obstructive disease might be the primary abnormality in these patients, with the ASD being an incidental, although exacerbating, finding. Also, other small published series showed that children with ASD II presenting in infancy with clinical symptoms are very heterogeneous regarding associated problems. Mainwaring and associates ${ }^{8}$ reviewed 6 symptomatic infants with isolated ASD who underwent early surgical closure. They report that 5 of 6 children demonstrated little or no improvement in symptoms and point out the frequent noncardiac basis of failure to thrive with an associated ASD in this patient group. Andrews and coworkers, ${ }^{9}$ who presented 6 patients after closure of symptomatic ASD in infancy, pointed out the need to search carefully for other underlying cardiac or pulmonary abnormalities. If other causes for pulmonary hypertension are excluded, they recommend closure of the ASD, although they emphasize that clinical symptoms might persist if other pathology is present.

Careful assessment of cardiac morphology is necessary to exclude left-sided obstructive cardiac malformations and additional shunts that might contribute to pulmonary hypertension. Regarding our patients with adverse outcomes (patient 4 , who died, and patient 22 , in whom pulmonary hypertension developed after ASD closure), it is remarkable that both patients are infants with Down syndrome. It is well known that these patients, even in the absence of structural heart disease, are at risk for development of persistent pulmonary hypertension. ${ }^{10}$ Histologic investigations suggest that the smaller number of alveoli and the smaller alveolar surface area accompanied by a loss of capillary surface area is responsible for the aggravation of pulmonary hypertension in this patient group. ${ }^{11}$ Looking retrospectively at the hemodynamic catheter data, patient 4 had a severely increased PVR $\left(11.6 \mathrm{E} \cdot \mathrm{m}^{2}\right)$, although responding to oxygen with a significant decrease in PVR. The other 2 patients (patients 15 and 16, both without Down syndrome) with markedly increased PVR are doing well postoperatively, without any sign of persistent pulmonary hypertension.

Patient 22 had no pulmonary hypertension preoperatively, and pulmonary hypertension was found at follow-up after ASD closure. It cannot be excluded that irreversible pulmonary vascular disease preexisted because of pulmonary hyperperfusion, which did not cause an increased PVR at the time of cardiac catheterization. In contrast, there is one patient with trisomy 21 in our patient group who is doing well after closure.

On the basis of the catheter data, there is no reliable marker that indicates whether closure of the ASD is safe. Therefore particularly in patients with Down syndrome, the indication for early ASD closure needs to be evaluated carefully.

Perhaps these patients should be considered for ASD closure with a fenestrated patch, subsequent close followup, and liberal use of vasodilation therapy.

The practical approach during the preoperative catheterization should include assessment of PVR and, if necessary, responsiveness to oxygen and nitric oxide. If a marked increase in pulmonary artery pressure, pulmonary artery resistance, or both without a response to oxygen and nitric oxide is noticed, ASD closure should not be performed. Also, if diminished pulmonary blood flow with cyanosis is present, the ASD should not be closed.

Left-to-right shunt, in addition to any pulmonary compromising factors, might accelerate and even enhance the progress of pulmonary vascular disease. In contrast to the majority of these lung diseases, such as dysplasia, the ASD is a problem that can be approached. For the majority of children, ASD closure in infancy has been beneficial; however, frequent clinical follow-up is essential to identify those patients who require additional therapy. Patients with preoperative pulmonary hypertension and those with signs of pulmonary hypertension after surgical intervention need repeated catheterization. Again, PVR studies are required to determine responsiveness to vasodilator therapy.

The natural history of these children is unknown, assessment is controversial, and often the decision for early closure of the ASD has been the result of an individual evaluation after long-standing intensive care treatment and exhaustion of conservative medical management. Although older reports ${ }^{12-15}$ focus on the postponement of surgical intervention, today the surgical risk is not a limiting factor. Regarding even major operations with cardiopulmonary bypass in infants with low weight, mortality has become low 
with increasing expertise over the last 20 years. ${ }^{16-18}$ Today, surgical intervention can be performed with a low risk, as we showed in our patient group of multihandicapped children with no perioperative mortality. It has been reported that interventional ASD closure is an option, even in small children. However, the vascular complication rate, ratio of device diameter to atrial septal diameter, loss of atrial motility, and atrioventricular valve dysfunction remain a problem. Therefore, we do not generally recommend an interventional approach in infancy.

After ASD closure, other clinical problems could be addressed. Physiotherapy or orthopedic treatment were facilitated after surgical intervention and led to a better clinical condition of these infants. Early closure of the ASD II seems to enhance the feeding situation and clinical performance and might also support better growth in these children. A special benefit was achieved in those children, who were dependant on artificial ventilation preoperatively, in whom weaning was successful shortly after surgical intervention.

\section{Limitations of the Study}

This is a retrospective study. Our patient group is very heterogeneous, which made it difficult to establish an appropriate control group because the majority of infants had syndromes or severe associated malformations that also have an effect on long-term survival and quality of life. Also, a randomized approach cannot be justified on obvious ethical grounds.

The use of normal percentiles for growth is disputable. Many of the syndromes are associated with syndromerelated growth retardation at different ages. However, percentile curves for these syndromes do not exist. Therefore even our finding that no catch-up growth is reached postoperatively can be misleading.

\section{Conclusions}

Closure of an ASD should not be postponed to a later age if clinical problems that can be attributed at least in part to the ASD are present. In the majority of patients, the PVR will return to normal after ASD closure, and the clinical condition will improve.

\section{References}

1. Hoffmann JIE. Incidence of congenital heart disease. I. Postnatal incidence. Pediatr Cardiol. 1995;16:103-13.

2. Chan KC, Godman MJ, Walsh K, Wilson N, Redington A, Gibbs JL. Transcatheter closure of atrial septal defect and interatrial communications with a new self expanding nitinol double disc device (Amplatzer septal occluder): multicentre UK experience. Heart. 1999;82: 300-6.

3. Zaver AG, Nadas AS. Atrial septal defect-secundum type. Circulation. 1965;32(Suppl):III24-32.

4. Bestermann E. Atrial septal defect with pulmonary hypertension. $\mathrm{Br}$ Heart J. 1961;23:587-98.

5. Campbell M. Natural history of atrial septal defect. Br Heart $J$. 1970;32:820-6.

6. Kuczmarski RJ, Ogden CL, Grummer-Strawn LM, Flegal KM, Guo SS, Wei R, et al. CDC growth charts: United States. Adv Data. 2000 Jun 8;(314):1-27.

7. Bull C, Deanfield J, de Leval M, Stark J, Taylor JFN, MacCartney FJ. Correction of isolated secundum atrial septal defect in infancy. Arch Dis Child. 1981;56:784-6.

8. Mainwaring RD, Mirali-Akbar H, Lamberti JJ, Moore JW. Secundumtype atrial septal defects with failure to thrive in the first year of life. J Card Surg. 1996;11:116-20.

9. Andrews R, Tulloh R, Magee A, Anderson D. Atrial septal defect with failure to thrive in infancy: hidden pulmonary vascular disease? $P e$ diatr Cardiol. 2002;23:528-30.

10. Shah PS, Hellmann J, Adatia I. Clinical characteristics and follow up of Down syndrome infants without congenital heart disease who presented with persistent pulmonary hypertension of newborn. J Perinat Med. 2004;32:168-70.

11. Cooney TP, Thurlbeck WM. Pulmonary hypoplasia in Down's syndrome. N Engl J Med. 1982;307:1170-3.

12. Wyler F, Ruitshauser M. Symptomatic atrial septal defect in the neonate and infant. Helv Paediatr Acta. 1975;30:399-408.

13. Spangler JG, Feldt RH, Danielson GK. Secundum atrial septal defect encountered in infancy. J Thorac Cardiovasc Surg. 1976;71:398-401.

14. Phillips SJ, Okies E, Henken D, Sunderland CO, Starr A. Complex of secundum atrial septal defect and congestive heart failure in infants. J Thorac Cardiovasc Surg. 1975;70:696-700.

15. Hunt CE, Lucas RV. Symptomatic atrial septal defect in infancy. Circulation. 1973;47:1042-8.

16. Beyens T, Bearnt D, Bouton JM, Demanet H, Viart P, Dessy H, et al. Cardiac surgery with extracorporeal circulation in 23 infants weighing 2500 g or less: short and intermediate term outcome. Eur J Cardiothorac Surg. 1998;14:165-72.

17. Haas F, Goldberg CS, Ohye RG, Mosca RS, Bove EL. Primary repair of aortic arch obstruction with ventricular septal defect in preterm and low birth weight infants. Eur J Cardiothorac Surg. 2000;17:643-7.

18. Reddy VM, McElhinney DB, Sagrado T, Parry AJ, Teitel DF, Hanley FL. Results of 102 cases of complete repair of congenital heart defects in patients weighing 700-2500 grams. J Thorac Cardiovasc Surg. 1999;117:324-31. 